\title{
Oceanography
}

CITATION

Caruso, M.J., M. Migliaccio, J.T. Hargrove, O. Garcia-Pineda, and H.C. Graber. 2013. Oil spills and slicks imaged by synthetic aperture radar. Oceanography 26(2):112-123, http://dx.doi. org/10.5670/oceanog.2013.34.

DOI

http://dx.doi.org/10.5670/oceanog.2013.34

COPYRIGHT

This article has been published in Oceanography, Volume 26, Number 2, a quarterly journal of The Oceanography Society. Copyright 2013 by The Oceanography Society. All rights reserved.

USAGE

Permission is granted to copy this article for use in teaching and research. Republication, systematic reproduction, or collective redistribution of any portion of this article by photocopy machine, reposting, or other means is permitted only with the approval of The Oceanography Society. Send all correspondence to: info@tos.org or The Oceanography Society, PO Box 1931, Rockville, MD 20849-1931, USA. 


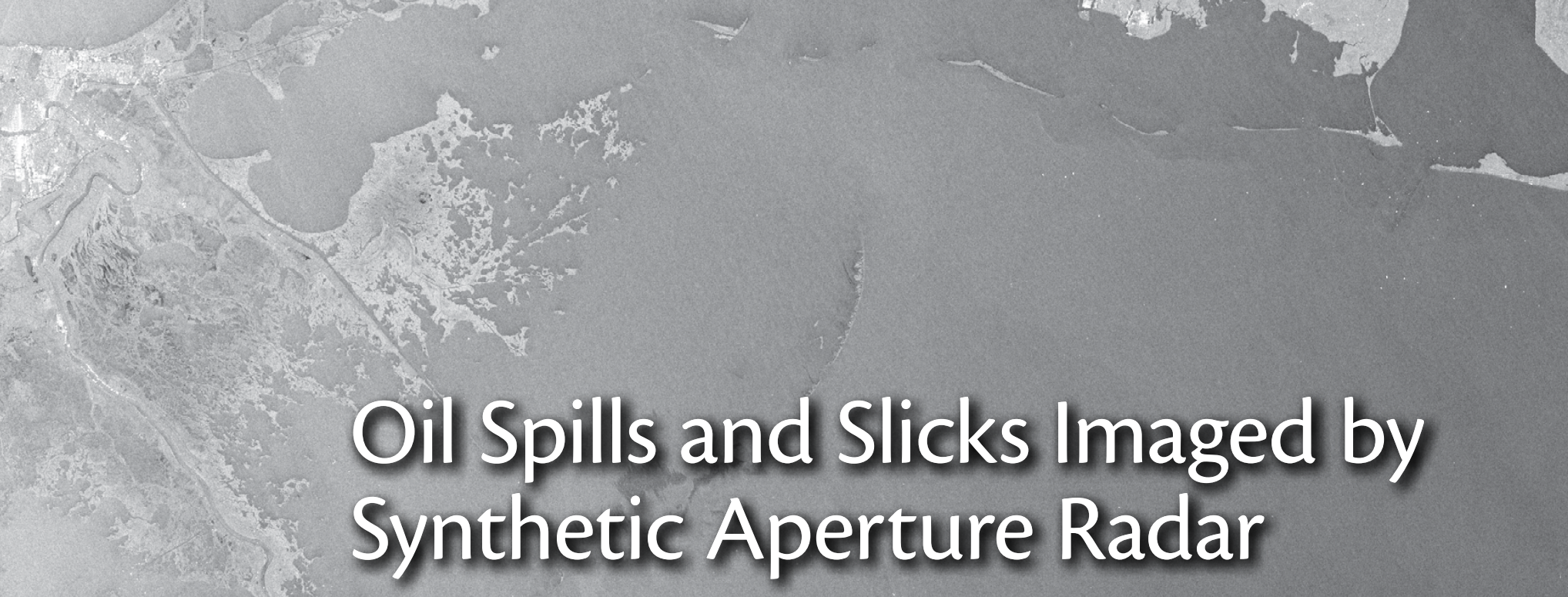

\section{Oil Spills and Slicks Imaged by Synthetic Aperture Radar}

BY MICHAEL J. CARUSO, MAURIZIO MIGLIACCIO, JOHN T. HARGROVE, OSCAR GARCIA-PINEDA, AND HANS C. GRABER

ABSTRACT. Oil spills and slicks occur in the ocean around the world due to natural seeps, oil extraction, transportation, and consumption. Satellite synthetic aperture radar (SAR) has proven to be an efficient tool for identifying and classifying oil on the sea surface. This information can be used to monitor areas for potential illegal marine discharge or to respond to an oil spill incident. When used to monitor shipping lanes or drilling platforms, timely analysis can identify offending parties and lead to prosecution. Following an oil spill such as that from the Deepwater Horizon rig in the Gulf of Mexico in 2010, SAR can be used to direct response activities and optimize available resources. 


\section{INTRODUCTION}

Natural seeps and activities associated with petroleum extraction, transportation, and consumption introduce oil into the marine environment. According to the US National Research Council (NRC, 2003), roughly one-third to onehalf of the oil discharged into the sea is from natural seeps, with the rest coming from anthropogenic sources. The threat to the environment from the various oil sources is difficult to determine and depends on the type of oil, its volume and location, duration of the seepage, and surrounding environmental conditions. Estimates of the volume of oil recovered after incidents such as the destruction of the Deepwater Horizon (DWH) platform in the Gulf of Mexico in 2010 or the grounding of the Exxon Valdez in Prince William Sound in 1989 are small compared to the total volume discharged (Fingas, 2013). Accidental and intentional discharges can cause significant damage to ecologically sensitive wetlands, coral reefs, and fishing grounds. Heavily oiled birds can die from hypothermia or from loss of buoyancy or ability to fly. Marine mammals can also die from hypothermia or may become easy prey. Long-term effects on fish and shellfish include reduced growth and reproductive impairment (NRC, 2003). Oil spillage in coastal waters can also directly impact the local economy by curbing activities such as fishing, boating, and tourism.

Although regulations have had a positive effect, difficult environmental conditions combined with human error and equipment failure preclude eliminating anthropogenic discharges of oil into the sea. Major accidents require extensive responses. The cleanup effort after the Exxon Valdez oil spill included more than 11,000 people and 1,400 vessels (Carpenter et al., 1991). After the DWH oil drilling platform at BP's Macondo well exploded and sank on April 20, 2010 , more than 47,000 people and 6,400 vessels were mobilized in a massive effort to contain and mitigate the effects of this environmental catastrophe (USCG, 2011). Mitigation efforts need to be strategically deployed to maximize resources and minimize the impact of the oil on the environment. An effective response to a marine oil spill depends on timely and accurate information about the location, extent, and characterization of the discharge.

Unfortunately, the amount and extent of oil in the marine environment is difficult to assess due to the lack of continuous and more efficient monitoring technology. In this regard, surveillance with synthetic aperture radar (SAR) is one of the most effective technologies to help identify and monitor oil on the sea surface over large remote areas. Since the launch of Seasat in 1978, there has been significant progress in the use of SAR on satellite platforms for the detection and characterization of oil on the sea surface. Internationally, the Canadian Ice Service (CIS) has implemented the Integrated Satellite Tracking of Pollution (ISTOP) program to monitor and survey areas of suspected pollution. This program uses satellite imagery to reduce

Michael J. Caruso (mcaruso@rsmas.miami.edu) is Senior Systems Engineer, Center for Southeastern Tropical Advanced Remote Sensing (CSTARS), Rosenstiel School of Marine and Atmospheric Science (RSMAS), University of Miami, FL, USA. Maurizio Migliaccio is Professor, Università di Napoli Parthenope, Napoli, Italy, and Faculty Associate, NOVA Southeastern University, Ft. Lauderdale, FL, USA. John T. Hargrove is Senior Software Engineer, CSTARS, RSMAS, University of Miami, FL, USA. Oscar Garcia-Pineda is Assistant Scholar/Scientist, Florida State University, Tallahassee, FL, USA. Hans C. Graber is Executive Director, CSTARS, RSMAS, University of Miami, FL, USA. 


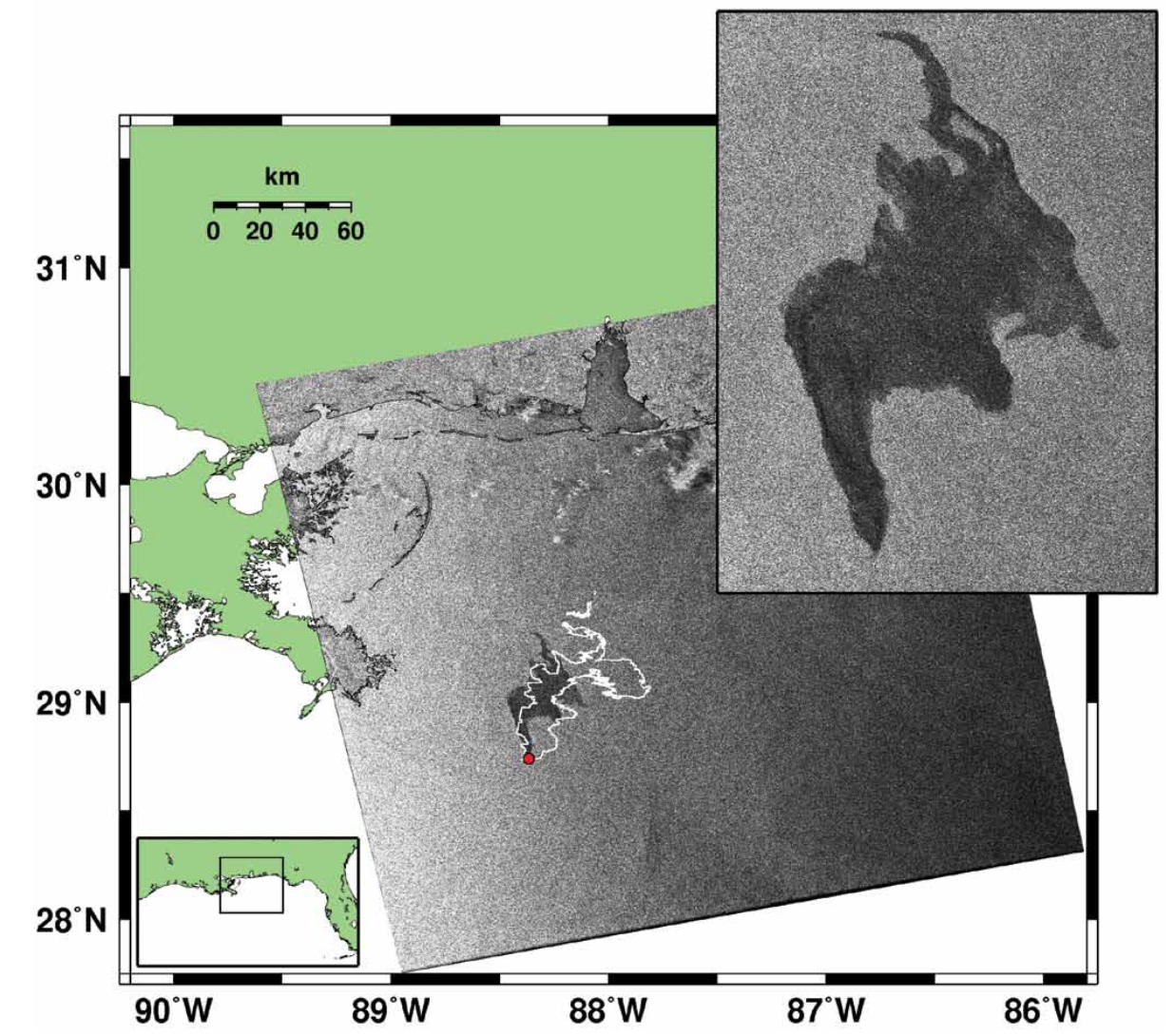

Figure 1. The first synthetic aperture radar (SAR) image following the Deepwater Horizon incident was acquired on April 23, 2010, and it showed oil on the sea surface propagating toward the coast (enlarged in inset). The white outline shows the extent of the oil on April 25, 2010, determined from a TerraSAR-X image. The red circle shows the location of the wellhead.

to the Florida Straits were collected by CSTARS, analyzed, and delivered to spill responders. To promote collaborative research, CSTARS has posted a large data set of this imagery, which can be viewed at http://www.cstars.miami.edu/ cstars-projects/deepwaterhorizon.

In addition to satellite SAR, numerous satellite and airborne remote-sensing systems were employed to observe the spread of oil during the DWH response (Leifer et al., 2012). These systems used passive or active sensing technologies, with each offering unique strengths and weaknesses for detecting and discriminating sources of oil in the marine environment. Oil spill detection and characterization efforts using satellite remote sensing have mainly focused on SAR because it can provide wide-area coverage during the day or at night, and it is not affected by cloud cover or fog (Fingas, 2013). There are still limits to the conditions where SAR can be useful for monitoring oil spills. In this paper, we provide an overview of the capabilities and shortcomings of using SAR observations to detect oil and slicks in the marine environment. We also summarize the various techniques for identifying oil in SAR imagery and discuss the advanced capabilities of the newest generation of satellite SAR instruments.

\section{SAR SENSORS}

SAR is an active microwave high-spatialresolution sensor that is at the core of any oil spill remote-sensing service. SAR sensors operate over a range of frequencies including $\mathrm{X}$-band $(8-12 \mathrm{GHz}$, $2.5-4 \mathrm{~cm})$, C-band $(4-8 \mathrm{GHz}, 4-8 \mathrm{~cm})$, and L-band (1-2 GHz, 15-30 cm). As an active sensor, the transmitted electromagnetic field is controlled in amplitude, phase, and polarization. These characteristics are also measured for the received field that, after proper coherent processing of the raw signal, yields a highspatial-resolution complex reflectivity map of the observed scene (Holt, 2004).

Image amplitude is a response to the microwave backscattering properties of the ocean surface. The backscatter measured by a SAR sensor is a function of radar incidence angle, which is the angle between the incident radar beam and the vertical to the intercepting surface (see Ager, 2013, in this issue, for a more detailed introduction to SAR imaging). At typical incidence angles ranging from $20^{\circ}$ to $60^{\circ}$, the response of a SAR to the ocean surface is due to Bragg scattering from surface gravity waves corresponding to the radar wavelength (Gade et al., 1998). These short surface waves are primarily a result of local wind stress. The viscoelastic property of oil on the sea surface dampens the waves by increased surface tension and reduced wind stress (Holt, 2004). This results in areas of reduced backscatter that appear as dark patches in the SAR images (Figure 2).

The antenna for a SAR system is designed so that the transmitted and received radar waves are vertically $(\mathrm{V})$ or horizontally $(\mathrm{H})$ polarized. The first satellite SARs were single-polarimetric sensors, in which the transmitted electromagnetic field had a fixed polarization co-polar to the one used in reception. In marine applications, the most appropriate single-polarimetric SAR mode is $\mathrm{VV}$, where the first $\mathrm{V}$ indicates transmission of an electromagnetic field temporally oscillating along a vertical (V) plane relative to the SAR antenna, and the second $\mathrm{V}$ indicates vertical 
received polarization. The new generation of satellite SARs has polarimetric diversity, featuring several unique sets of polarimetric modes. Single polarization is no longer limited to co-polarized images-a cross-polarized image such as VH or HV can now be obtained. In dualpolarimetric coherent mode, one linear polarization is transmitted and two linear polarizations are received coherently, for example, HH-HV, VV-VH. Finally, in the full-polarimetric mode, the SAR antenna transmits and receives vertically and horizontally polarized electromagnetic fields so a full scattering matrix is measured, resulting in $\mathrm{HH}, \mathrm{VV}$, $\mathrm{HV}$, and VH images. This mode is currently available with RADARSAT-2 and TerraSAR-X.

Current satellite SAR sensors have the capability to image at different spatial resolutions with corresponding spatial coverage. Particular combinations of incidence angle, polarization, and spatial resolution are more or less suitable depending upon the application. The specific imaging region can be selected using the appropriate beam mode. The different beam modes are characterized by the range of incidence angles and the effective spatial resolution. The single beam mode provides the highest resolution and has the smallest spatial extent. The ScanSAR mode combines multiple single beams, which inherently reduces the Doppler bandwidth. It produces a larger imaging area with a lower spatial resolution.

For marine environmental monitoring, the so-called ScanSAR modes with resolutions of 20-60 $\mathrm{m}$ and swath widths of 100-300 km provide an ideal trade-off between spatial resolution and areal coverage. This resolution is adequate for identifying most marine anomalies. Figure 3 shows an example of ship discharge in the South China Sea from an ERS-2 SAR image acquired on May 25, 2007, with a resolution of $30 \mathrm{~m}$. The discharge behind the southern ship in the image shows the characteristic long and narrow dark areas trailing the ship. The northern ship has a similar trail that shows feathering of the discharge by wind from the south. The lower-resolution ScanSAR modes with 75-150 m resolution and 200-500 km swath width can locate some larger anomalies, but are not adequate for identifying details in them.

The higher-resolution Stripmap $(\sim 3-5 \mathrm{~m})$ and Spotlight $(\sim 1-3 \mathrm{~m})$ modes are useful for identifying suspected discharge and mapping oil reaching the coast or in harbors or estuaries. However, with swath widths of just $\sim 30-50 \mathrm{~km}$ and $\sim 10 \mathrm{~km}$, respectively, these modes require that a specific area be targeted by the sensor. Highresolution imagery was used after a towboat struck an abandoned well head in Mud Lake, LA. The Figure 4 TerraSAR-X spotlight image, acquired on August 1, 2010, shows the network of bayous and lakes surrounding the wellhead. The oil has impacted the coastline with filaments of oil spreading southeast toward the ocean.

\section{SAR IMAGING OF OIL ON THE SEA}

The imaging of oil on the sea surface with SAR relies on the damping effect of the oil on the Bragg waves. Unfortunately, the reduced radar backscatter on the sea surface is not unique to oil. Low winds, biogenic films, wind sheltering by land or oceanic structures, grease ice, internal waves, ship wakes, and convergence zones also create areas of reduced radar backscatter.

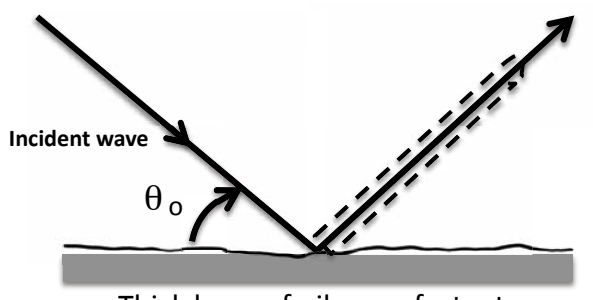

Thick layer of oil or surfactant

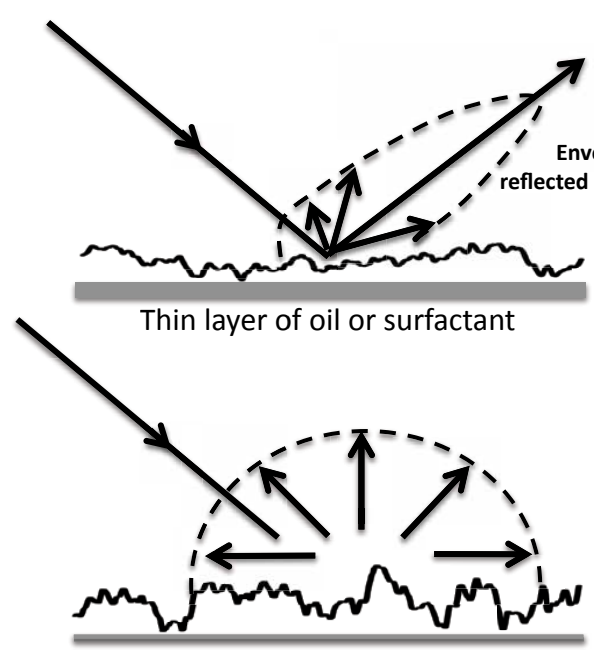

Oil Sheen or no oil present
Figure 2. The variation of radar backscatter due to oil or surfactant on the sea surface. A thick layer of oil or surfactant reflects the radar energy away from the incident wave and produces no backscatter. A thin layer of oil reflects a small part of the energy back toward the SAR. An area with a thin sheen of oil or with no oil reflects the most energy. 


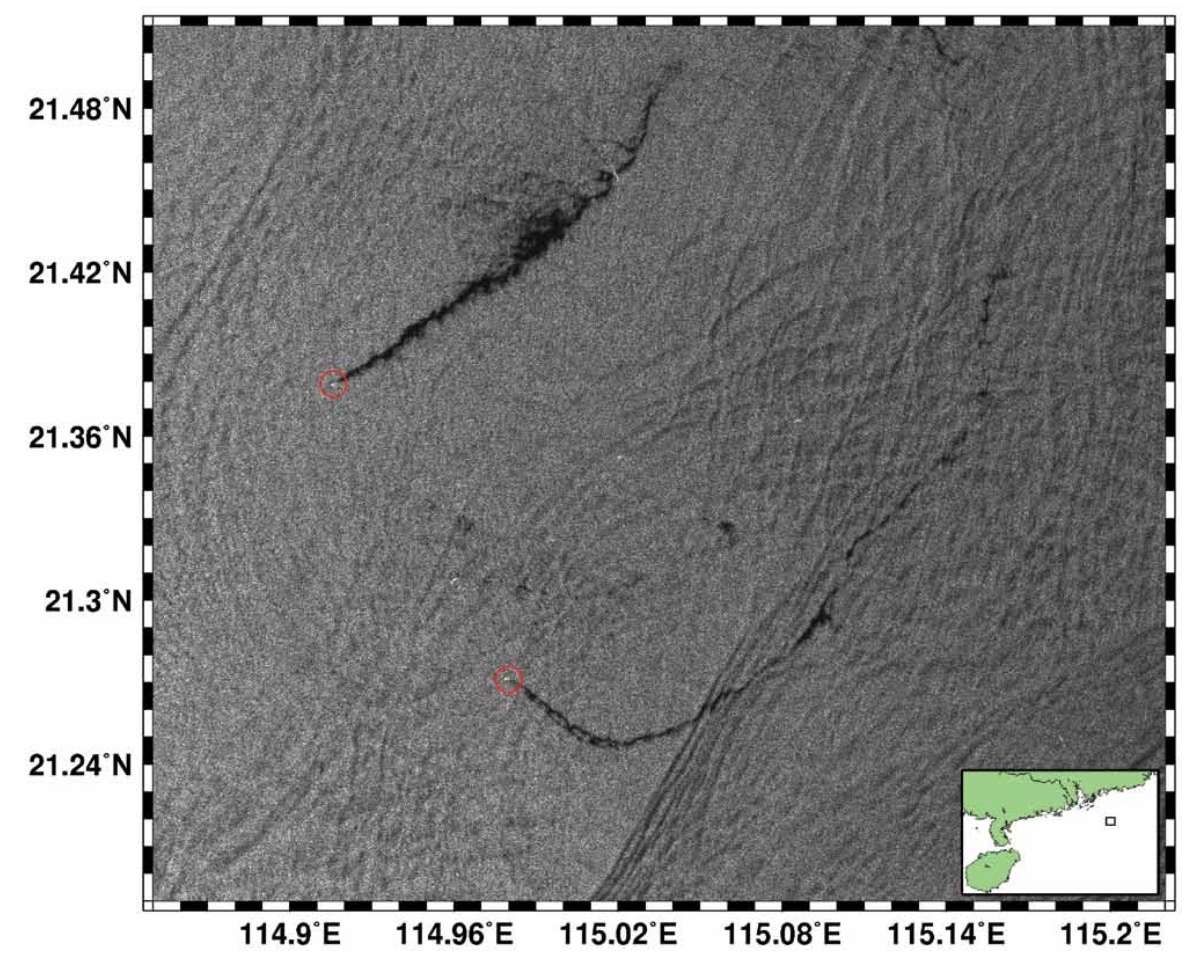

Figure 3. An ERS-2 SAR image from May 25, 2007, at 14:44 GMT, showing illegal discharge from two vessels (circled) in the South China Sea. This type of oil spill is characterized by a thin trail following the path of the ship. Internal waves are interacting with the southern ship's tail of oil. The northern ship trail also exhibits feathering of the oil from a southern wind.

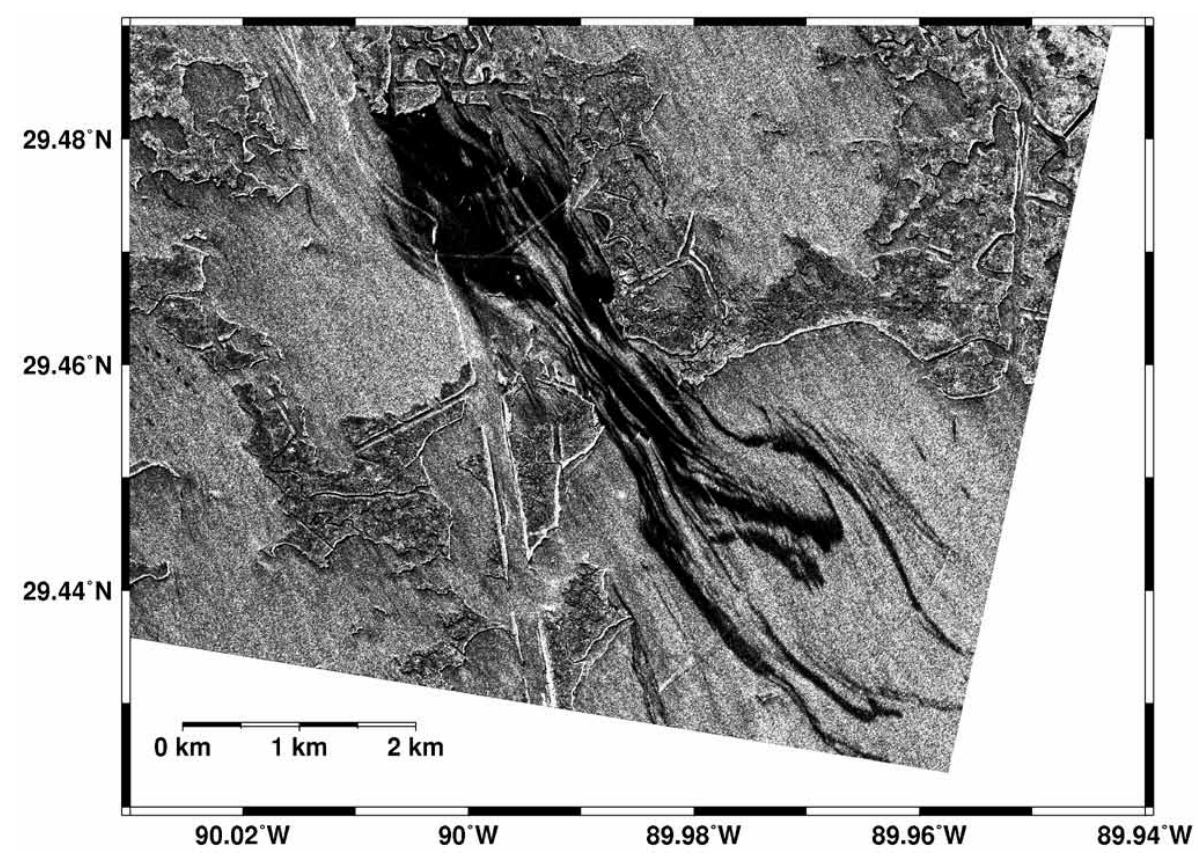

Figure 4. A TerraSAR-X spotlight image from August 1, 2010, at 12:08 GMT shows the spread of oil after the tugboat Pere Ana C. struck a wellhead near Mud Lake, LA. The highresolution spotlight mode helps map areas of coastal marshland impacted by the oil leak.
Thunderstorms, rain, and atmospheric and oceanic fronts can mask surface roughness or produce so-called "lookalike" features (Figure 5). Furthermore, oil on the sea surface is subjected to a number of processes that include evaporation, dispersion, emulsification, dissolution, oxidation, sedimentation, and biodegradation. These physical, chemical, and biological processes make the discharged oil undetectable over time (Alpers and Espedal, 2004). For these reasons, the detectability of oil with SAR is sensitive to the source of the oil, the current environmental conditions, and the history of the sea surface in localized areas (Espedal, 1999).

The detectability of oil with SAR is also dependent on the sensor configuration. For C-band SAR, the detectability is dependent on polarization, incidence angle, spatial resolution, and noise equivalent sigma zero (NESZ; Cheng et al., 2011). For single polarization images, VV-polarization produces better results than $\mathrm{HH}$-polarization. The backscatter intensity decreases with increased incidence angle; therefore, small spills cannot be discriminated with lower-resolution beam modes. Although the NESZ (a measure of the sensitivity of the SAR system) potentially limits the effectiveness at high incidence angles, the effects of wind speed are more important (Cheng et al., 2011).

When ocean surface winds are calm, surface gravity waves disappear, the returned radar backscatter is low, and the ocean surface appears featureless and uniformly dark across the image. As the winds increase to about $3 \mathrm{~m} \mathrm{~s}^{-1}$, biogenic slicks begin to appear. Biogenic surface slicks such as those produced by plants and animals in the ocean can also dampen radar return and cause 
look-alike false alarms for oil detection (Gade et al., 1998). At the lower end of this range, biogenic slicks blend in with the low wind regions of the image. As the winds reach 2-3 $\mathrm{m} \mathrm{s}^{-1}$, these slicks begin to highlight oceanic convergence zones along fronts and eddies. At these speeds, it is often difficult to distinguish biogenic slicks from anthropogenic oil or natural seeps. When the winds begin to exceed $3 \mathrm{~m} \mathrm{~s}^{-1}$, the biogenic slicks start to disappear and the contrast between oil and the sea surface is very strong. As the winds continue to increase, the short surface waves produce stronger radar backscatter. When the wind speed is greater than about $8-10 \mathrm{~m} \mathrm{~s}^{-1}$, mixing by strong wind and/or wave action inhibits the formation of a surfactant layer, resulting in uniformly strong backscatter in all areas of an image so that oil cannot be detected.

The discrimination of illegal marine discharges is further complicated in areas of natural hydrocarbon seeps. Because seeps are associated with potential energy reserves (Garcia-Pineda et al., 2010), oil drilling platforms are often located nearby. Oil from natural seeps is frequently observed with SAR, and has characteristics similar to anthropogenic spills. Although many naturally occurring seeps are persistent and can be identified using repeated image acquisitions, distinguishing between spilled oil and naturally occurring oil is not always possible.

\section{OIL DETECTION METHODS}

Routine use of SAR for monitoring marine pollution began with ERS-1 in 1993 over Norwegian waters. Trained operators were used to identify potential pollution, and an aircraft was available to investigate slicks detected by the operators (Wahl et al., 1994). Because SAR imagery frequently contains false signatures and the ancillary information required to interpret SAR imagery takes varied forms, oil detection with SAR has typically been performed by an expert human analyst who can interpret contextual information. Automated techniques are highly desirable because they eliminate subjective interpretation. However, operational services typically use automated techniques supervised by an expert operator.

Although the details vary for each oil detection system, SAR oil detection algorithms generally have the same basic components: region selection, feature extraction, and spill classification (Brekke and Solberg, 2005; Topouzelis, 2008). These components are similar for systems that use expert operators, automated techniques, or a supervised process.
Region selection is the segmentation of contiguous dark pixels in an image using various thresholding, edge detection, and clustering techniques. This step is critical and difficult, and it must be successful in order to use automated extraction techniques. The coherent interference of the ocean surface produces a "salt and pepper" appearance, referred to as speckle (McCandless and Jackson, 2004). The inherent speckle creates a large standard deviation in a SAR image and must be eliminated without removing small dark regions. This is commonly done using multiple looks, noise reducing filters, or a speckle model (Migliaccio et al., 2007a). The dark region selections primarily focus on statistical analysis of image intensity. These techniques include bimodal, adaptive, nonadaptive, and hysteresis thresholding (Brekke and Solberg, 2005). To utilize additional information about

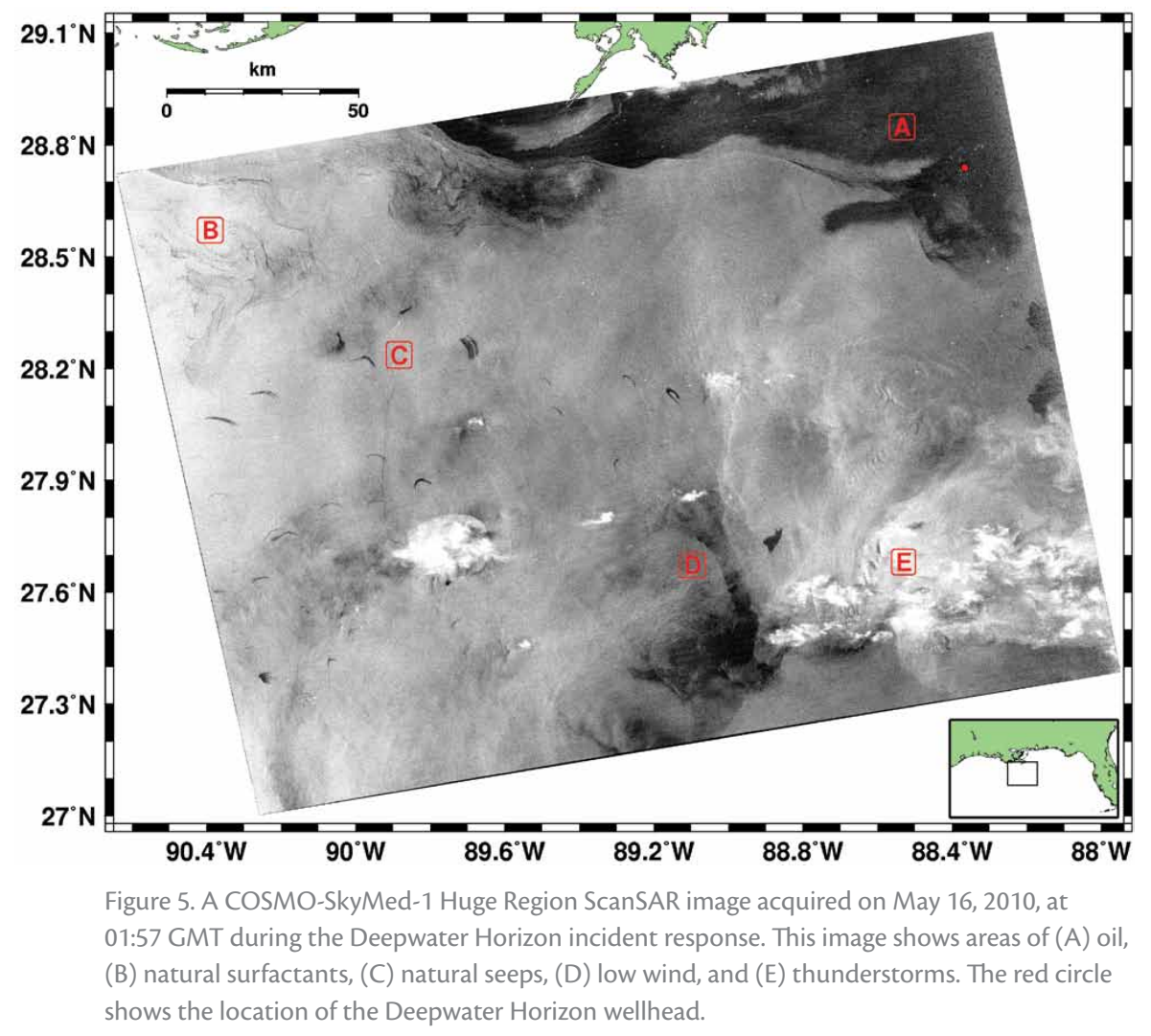


the environment and the sensor, GarciaPineda et al. (2009) developed a texture classifying neural network algorithm (TCNNA). This neural network uses edge-detection filters, texture, sensor details, and environmental data to delineate dark areas (Garcia-Pineda et al., 2013). Polarimetric data can also be used with a constant false alarm rate (CFAR) filter to detect dark areas (Migliaccio et al., 2007b). Trained operators may use one or more of these methods interactively to visually highlight areas with low contrast for analysis.

Feature extraction involves a variety of characteristics and is highly dependent on the approach. Physical characteristics include various measures of backscatter intensity within dark regions relative to their local background. Geometric features include simple measures like size, shape, and perimeter, as well as higher-order variations within the dark region (texture). Context features incorporate the proximity of the region to ships, shipping lanes, drilling rigs, subsea pipelines, and natural hydrocarbon seeps. Expert operators may also use these features.

Finally, spill classification is the analysis of each dark region's features for the purpose of classifying the region as either a spill or a look-alike. These techniques are generally based on statistics, neural networks, or fuzzy logic. Topouzelis (2008) provides a comprehensive summary of classification methods. Gambardella et al. (2010) show that classifying dark regions as either spill or look-alike, a "two-class" approach, is inferior in performance to a "one-class" approach, in which all dark regions are considered oil, and the onus is on the dark region formation step to eliminate look-alikes.
MONITORING AND RESPONSE An operational satellite SAR oil spill system can be organized into monitoring and response activities. Monitoring is used to detect unknown microspills and typically involves systematic imaging of shipping lanes, subsea structures, and areas with drilling activities. The ScanSAR image mode is preferred for monitoring areas for unreported discharges because it provides an optimal compromise between spatial coverage and resolution. Repeat coverage, combined with automated detection techniques, is an effective tool for identifying potential illegal marine discharge. An automated alert can be used to trigger a visual investigation or additional SAR acquisitions. Response is appropriate when an oil spill has been detected or reported. When the specific area is known, the imaging parameters can be customized for the type and extent of the spill. For example, higher-resolution spotlight or stripmap imagery can be acquired to monitor coastal spills where broad spatial ScanSAR coverage is not needed.

The complete process, diagrammed in Figure 6, begins with a feasibility analysis over the monitored area to determine the specifications for the SAR image order to be placed with the satellite vendor. The image is then acquired by the satellite and downlinked to a receiving station where a normalized radar cross section (NRCS) image is produced and processing artifact filters are applied. The ScanSAR imaging mode extends the effective swath width of a SAR sensor by scanning across multiple subswaths in an alternating manner. This processing produces detectable discontinuities at the beam locations and a wave-like modulation known as scalloping (Romeiser et al., 2013). These image artifacts appear as linear edges that may be interpreted as an interface between oil and water by detection algorithms.

The next stage of the process is wind and wave retrieval. Wind direction may be obtained from wind streaks in the image, from meteorological buoy measurements, from satellite scatterometer wind products, and/or from an atmospheric circulation model output. Wind speed is also calculated using model functions based on NRCS, polarization, antenna look direction and incidence angle, and wind direction (Horstmann and Koch, 2005).

Depending on the oil detection technique, secondary information may be acquired to aid in the interpretation of the image. Satellite sea surface temperature and ocean color may be used to identify fronts, eddies, and upwelling regions. Weather radar is useful for identifying rain and thunderstorm activity. Coastal radar and regional ocean circulation model output can be used to identify ocean fronts, eddies, currents, and temperatures. Databases of known seep locations, shipping lanes, subsea pipelines, wellheads, and drilling rigs are also beneficial for interpreting SAR imagery.

The image is then enhanced to sharpen the gradients surrounding the dark areas of the image and image characteristics that are used by the analyst or the detection algorithm. In a review of techniques, Solberg (2012) listed 29 characteristics for single-polarization data that are useful for identifying dark areas of an image.

The basic output from an oil detection algorithm is a polygon delineating the region or regions classified as oil. This product can be incorporated into Google Maps or other geographic 
information systems (GISs). These maps can then be incorporated into PowerPoint briefings for response officials (this was done daily during DWH) and shared with the public on the Internet (the CSTARS website received heavy traffic during DWH). An important additional product is a map showing where the SAR imaged, where it did not image, and where it imaged but was not able to perform an oil assessment for reasons described below. Of course, in a monitoring scenario in which no oil spill was detected, this would be the only product. Finally, we note that eventually SAR oil detection products may also be exported to oil trajectory forecast models.

\section{Deepwater Horizon Response}

The Deepwater Horizon oil rig, located $75 \mathrm{~km}$ southeast of the Mississippi Delta, exploded and caught fire on April 20, 2010. The response process began with a feasibility analysis over the monitored area. For the initial response, this area was about $400 \mathrm{~km}^{2}$. In addition to the RADARSAT-2 ScanSAR Narrow image (60 $\mathrm{m}$ resolution, $300 \mathrm{~km}$ swath width), a TerraSAR-X ScanSAR image $(18 \mathrm{~m}$ resolution, $100 \mathrm{~km}$ swath width) was also ordered for April 25, 2010. The RADARSAT-2 image (Figure 1) showed that oil covered approximately $800 \mathrm{~km}^{2}$ and extended more than $65 \mathrm{~km}$ toward Mobile Bay. The rig sank on April 22, 2010, and it appeared that the leaking wellhead would be difficult to repair. By April 25, 2010, the area of the oil had increased to $1,200 \mathrm{~km}^{2}$ and extended more than $90 \mathrm{~km}$ from the source (Figure 1, white outline).

With the ability to plan, downlink, and process data from 14 optical and SAR satellites, CSTARS was in a unique position to provide near-real-time imagery and analysis. On April 29, 2010, CSTARS began coordinating with the US government to acquire, analyze, and distribute daily systematic satellite imagery of the oil spill. A COSMO-SkyMed-1 WideRegion image (30 $\mathrm{m}$ resolution, $100 \mathrm{~km}$ swath width) and a TerraSAR-X ScanSAR image were acquired on the morning of April 30, 2010, less than two minutes apart. These overlapping images showed identical oil spill areas and that the spill had extended more than $12 \mathrm{~km}$ south, $58 \mathrm{~km}$ north, $60 \mathrm{~km}$ west, and $45 \mathrm{~km}$ east. A second COSMOSkyMed-1 image acquired 12 hours later showed similar features. This sequence of images demonstrated that the surface oil area was rapidly changing and that the monitored area needed to be

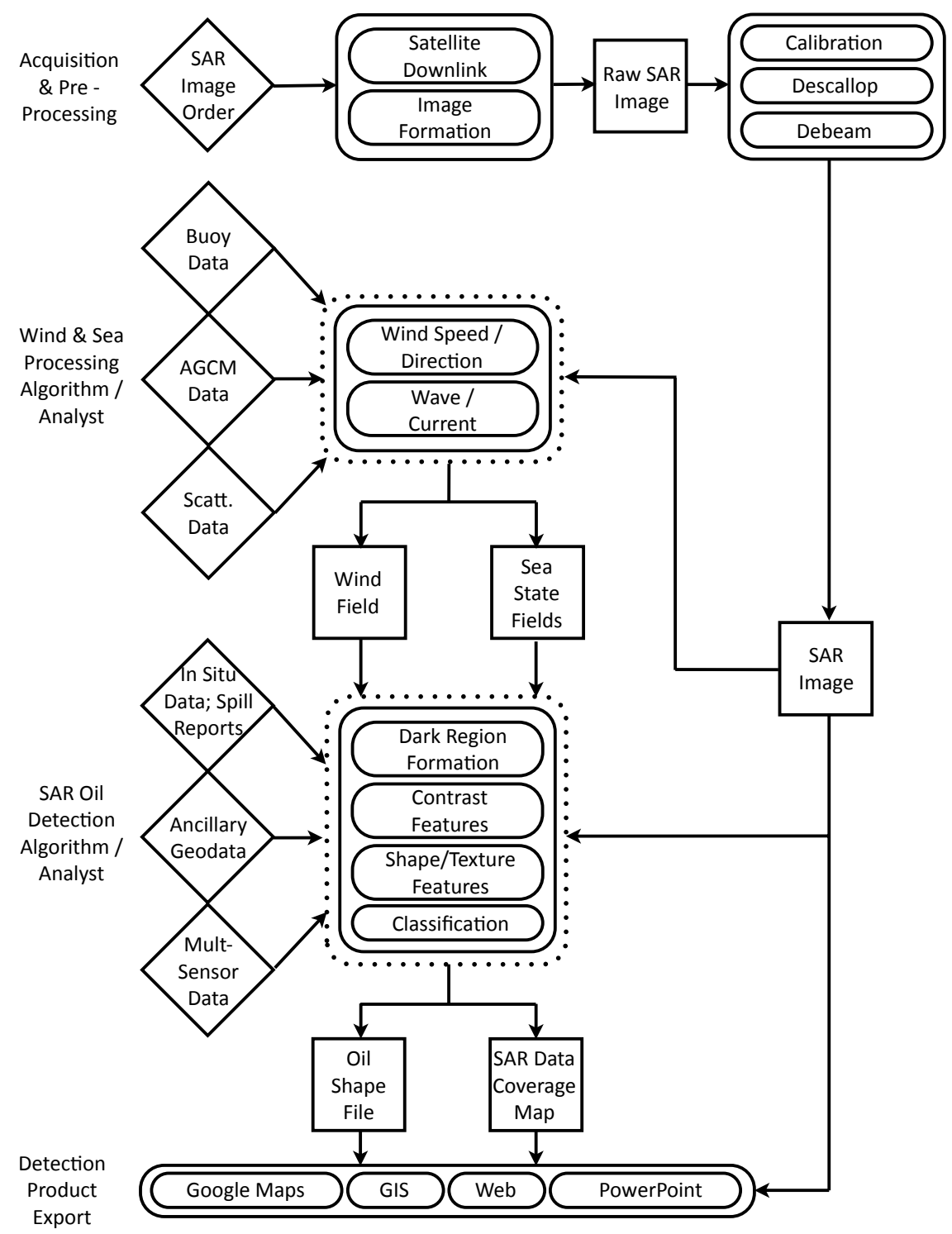

Figure 6. The Satellite SAR Oil Detection System flowchart. The leftmost column provides names of main processing stages. Diamonds are inputs and squares are outputs (and inputs). Rounded rectangles are processes and subprocesses. Processes surrounded by dotted lines may be fully automated, semi-automated, or performed by a human analyst. 
expanded. Multiple satellites would be required to provide daily coverage of the oil spill's extent.

These images clearly showed the effects of winds and tides. Between April 23, 2010, and April 25, 2010, the winds were generally moderate at $7-10 \mathrm{~m} \mathrm{~s}^{-1}$ from the south. The prevailing winds pushed the oil slick northward toward the coast, creating an elongated shape. Between April 26, 2010, and April 28, 2010, the winds remained moderate, but were essentially from the west. The winds then increased to $12 \mathrm{~m} \mathrm{~s}^{-1}$ and shifted from west to southeast, producing a large circular spill area northwest of the wellhead with multiple filaments north and east of the main spill. The second COSMO-SkyMed-1 image acquired on April 30, 2010, showed the northern edge of the spill area spreading northwest from the influence of the southeast wind.

The central spill area continued to exhibit an eddy-like structure with clear

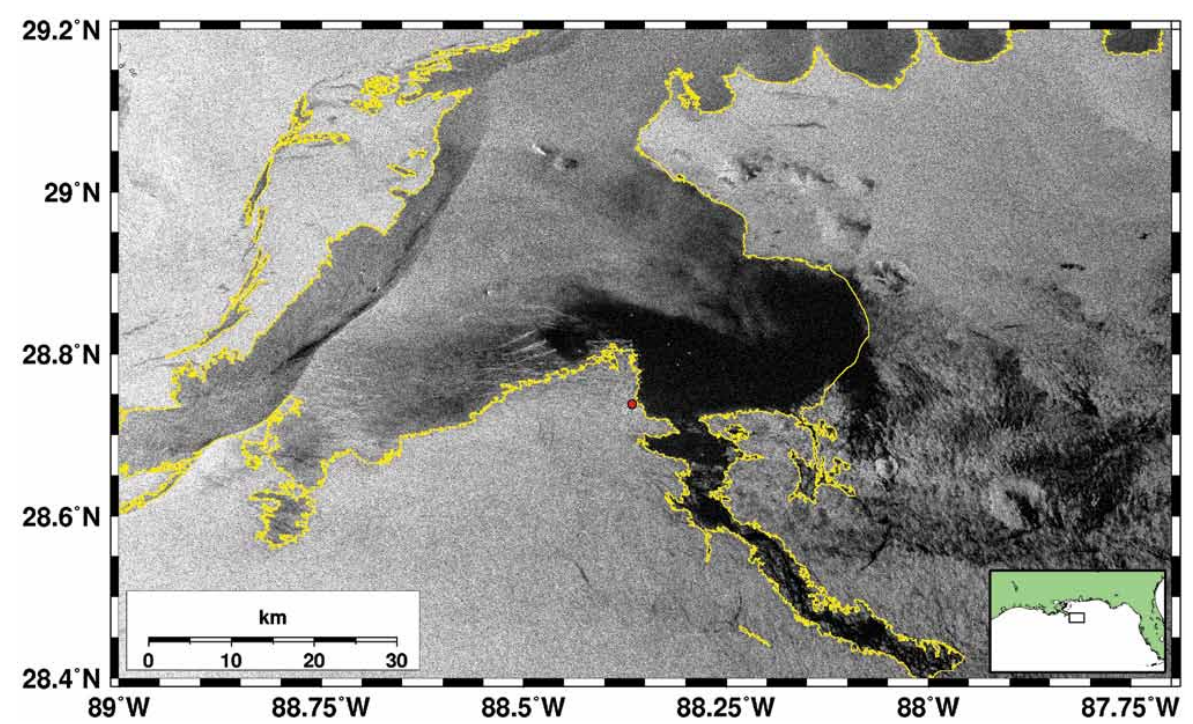

Figure 7. A satellite SAR image from RADARSAT-2 acquired over the Deepwater Horizon platform location (red circle) on July 4, 2010, at 23:47 GMT. In this image, a front is visible across the northwestern part of the image. The effects of the skimmers are clearly visible to the northwest of the platform location. The yellow line shows the outline from the Textural Classifier Neural Network Algorithm. Small areas identified by the algorithm in the interior of the outline have been removed for clarity. The dark areas in the southeast corner of the image are areas of low wind and were not classified as oil by the algorithm. filament of oil as it continued to extend southeastward. This filament was also identified in MODIS optical imagery and continued to be visible with SAR until May 22, 2010.

After the initial images were acquired and it was determined that the oil spill area was rapidly expanding, the monitored area was increased to $360,000 \mathrm{~km}^{2}$ and reached from the Louisiana-Texas border to the Florida Panhandle. When oil was observed advecting westward toward Texas and offshore toward the Gulf of Mexico Loop Current, the area was expanded again to cover the coast from Galveston, Texas, to the Florida Keys. During June, the oil spill area could be characterized as a large, dynamic central region with multiple filaments that would detach and advect away from the core. Throughout the month, filaments were frequently seen impacting the shoreline from Marsh Island, Louisiana, to Pensacola, Florida.

Figure 7 shows how SAR was used to monitor cleanup efforts. Skimmers began working in the area west of the wellhead on July 2, 2010, in an area heavily covered in oil. Two days later, on July 4, 2010, the core of the oil had advected to the east of the wellhead. The linear signatures of the skimmers are visible northwest of wellhead. This figure also shows a yellow line delimiting the main area of the oil spill produced by a textural classifier neural network algorithm analysis, which differentiates the surface oil north and west of the wellhead from the low wind area 20-30 km to the southeast.

The daily oil spill areas estimated during the response showed a growth rate of $530 \mathrm{~km}^{2}$ per day between April 2010 and July 2010. The variability of the area estimates increased in June corresponding to an increase in the number of 
low-wind days. The growth rate was consistent until July when three hurricanes passed through the Gulf of Mexico. After the leak was plugged on July 15, 2010, the oil spill area slowly decreased into August 2010, when satellite observations were suspended.

\section{FUTURE DEVELOPMENTS}

New developments in both space and ground segments may soon result in a new era of operational services. On the space side, next-generation satellites will feature new imaging modes, further discussed below. Improvements in oil detection will also come from the ground segment, with enhancements in processing algorithms. Operational oil spill services are still largely based on the use of single-polarimetric SAR amplitude images (Solberg, 2012). The use of multilook to reduce speckle in amplitude images has the effect of degrading spatial resolution, however, full-resolution single-look SAR imagery containing speckle can be effectively used by proper modeling of the speckle process (Migliaccio et al., 2007a). The benefits to be gained from the use of more than a single polarization (i.e., polarimetric SAR) were first shown in Migliaccio et al. (2007b), but to fully utilize polarimetric SAR, the amplitude data are insufficient. Complex data must be used because the phase difference between polarizations contains valuable information.

Experiments with both airborne and spaceborne L-, C-, and X-band data demonstrate that Bragg scattering does not occur for surfactants with strong damping properties, such as oil. The low return signal is from non-Bragg scattering. Surfactants such as biogenic films have weak damping properties. While the return signal is also low, it is still the result of Bragg scattering, as in the case of the open-ocean surface. This difference can be exploited using polarimetric SAR by measuring correlation between polarizations, which will be different for Bragg and non-Bragg scattering. Filters based on this concept have been developed and tested. For dual-polarimetric images, the filters use co-polarized phase difference (CPD), the standard deviation of the phase difference between the $\mathrm{HH}$ and VV channels (Migliaccio et al., 2009; Velotto et al., 2011). For full-polarimetric SAR, the filters are based on a polarimetric scattering matrix (Nunziata et al., 2013). It must be noted that low-wind areas are characterized by a scattering mechanism indistinguishable from that of oil, and, therefore, even with polarimetric SAR, it is the lowwind look-alikes that must be identified with ancillary information and/or a morphological model.

Figure 8 provides an example of the benefits of polarimetric SAR, where speckled SIR-C (Spaceborne Imaging Radar) C-band SAR amplitude images are shown. In both cases, there is a dark area that needs to be classified as an oil spill or a look-alike. The randomness of the dark patch in Figure 8a suggests a natural phenomenon as a source, as opposed to Figure 8b, which looks ordered and man-made. Appearances can be deceiving. In fact, both are manmade, but (a) is an oil spill while (b) is a simulated biogenic film. This can be seen by applying the CPD filter, whose output is shown in Figure 8c,d. The dark patch in Figure 8a appears as a bright patch in Figure $8 c$, indicating oil. The dark patch in Figure 8b is also dark in Figure 8d, indicating that it is a biogenic film, while a ship that is present is clearly emphasized. Quantitative details for this example are found in Migliaccio et al. (2009), but the clear visual difference in CPD filter output between oil and biogenic
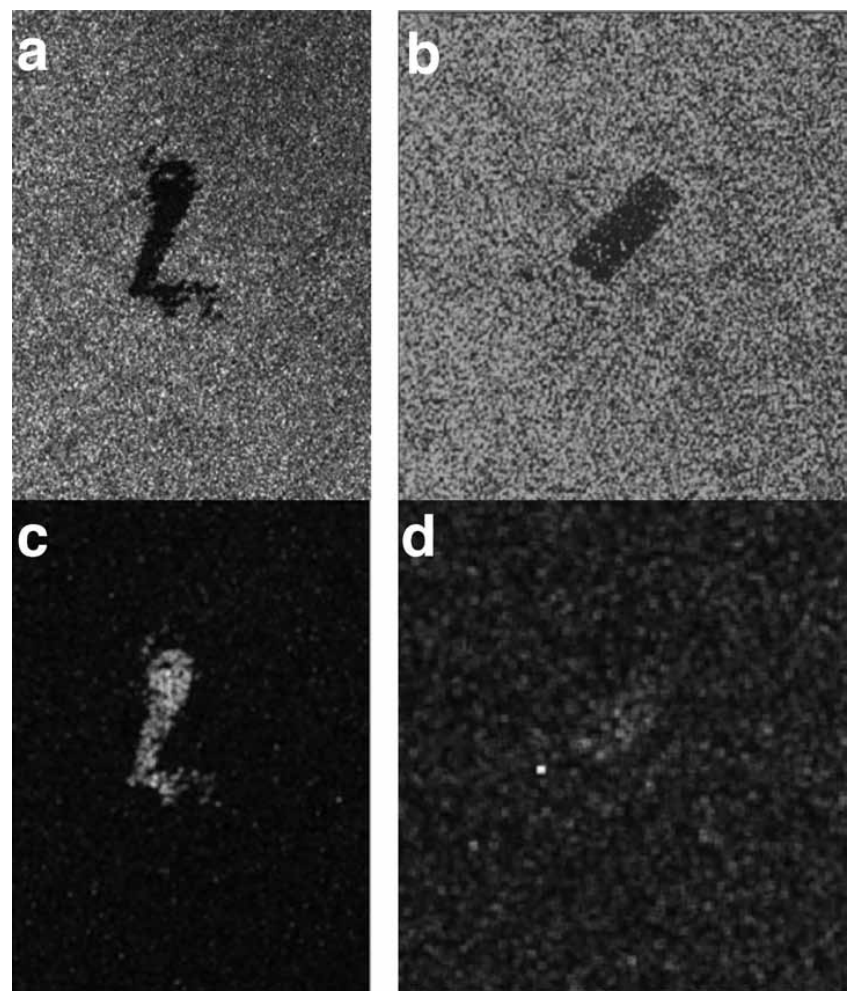

Figure 8. The SIR-C C-band SAR amplitude images acquired on (a) October 1, 1994, at 08:14 UTC, and (b) on April 15, 1994, at 02:14 UTC. The corresponding estimated standard deviation of the co-polarized phase differences are shown in (c) and (d) for the images in (a) and (b), respectively. 
film makes this method easy to interpret even for the non-expert.

Nunziata et al. (2012) provide a unified physical view of most of the polarimetric SAR approaches. Intercomparison of single, dual, and full polarimetric SAR must consider several aspects that include swath size and resolution, as well as data availability. At this time, full polarization is not possible for the imaging modes with the greatest areal coverage. Thus, advances in polarimetric SAR sensor design for use on satellites are encouraging. The socalled compact and hybrid polarimetric modes (Raney, 2007) have the potential to combine multiple polarization with high spatial resolution and large swath. The hybrid mode is especially promising, and an infrared sensor will be operated onboard future L- and C-band SAR missions. The staggered SAR mode (Villano et al., 2012) is a concept mode with design benefits comparable to hybrid mode. These technology developments will allow the full capability of polarimetric SAR oil detection to be applied for wide-area surveillance of the ocean.

\section{SUMMARY}

Pollutants at sea are an unfortunate consequence of the world's dependence on fossil fuels to meet its energy needs.

Demand for these products is unlikely to diminish in the foreseeable future. This is a reality that will continue to drive the exploration, extraction, and transportation of oil across the ocean, which will inevitably produce new oil spills. To mitigate the effects of these environmental catastrophes, satellite SAR provides a valuable tool both to monitor large areas of the ocean surface on a routine basis and to direct the response in the event of a crisis.
All remote-sensing instruments have strengths and weaknesses when used to detect and characterize oil on the sea surface. The effectiveness of a single SAR satellite is limited by the rate at which it revisits the spill area. However, with an unprecedented nine SAR satellites tasked for a single event, the response to DWH demonstrated what is possible. Acquisition from seven to $10 \mathrm{SAR}$ satellite passes per day from COSMO-SkyMed-1/2/3, ERS-2, Envisat, PalSAR, RADARSAT-1/2, and TerraSAR-X provided a combination of high-resolution $(\sim 1 \mathrm{~m})$ images to assess oil spreading in estuaries, and lower resolution ( 10-100 m) ScanSAR images to monitor the wider northern Gulf of Mexico. Using the current constellation of COSMO-SkyMed, RADARSAT-2, and TerraSAR-X satellites, a typical area over the Mediterranean Sea could be monitored approximately three times per day. The planned launches of the RADARSAT Constellation, Sentinel-1, and PAZ radar satellites will extend this constellation. A constellation of satellite SAR provides the core of a practical and cost-effective system that works synergistically with airborne remote sensing and in situ observations for global surveillance.

SAR is inherently limited by the environmental conditions at and around the oiled sea surface. High winds severely limit its effectiveness, while low winds and the biogenic surfactants that thrive in these conditions may exaggerate or mask the extent of a spill. But since satellite SAR was first used for oceanic oil detection, the technology and utilization methods have improved continuously. Full exploitation of the information provided by the polarimetric sensors of today and tomorrow provides a promising avenue for performance improvement. New algorithms, developed from approaches as varied as physics-based speckle models, to machine learning of the features that distinguish spilled oil, are also expected to expand the conditions in which SAR imagery is useful. Nearreal-time algorithms coupled with an increasing number of SAR images will allow operational centers to quickly analyze ever-larger areas of the ocean surface. Operational oil detection centers can use this information in conjunction with auxiliary satellite and in situ data to expediently provide source and extent to those tasked with coordinating responses. Timely updates are vital because the transport and fate of spilled oil changes by the hour.

\section{ACKNOWLEDGEMENTS}

The authors would like to thank the staff at CSTARS for their efforts during the DWH response. We would also like to thank MacDonald, Dettwiler and Associates Ltd. for the RADARSAT data, Infoterra $\mathrm{GmbH}$ for the TerraSAR-X data, and the European Space Agency for the Envisat data used in this manuscript. This research was made possible by a grant from BP/The Gulf of Mexico Research Initiative under Grant \# GoMRI-023.

\section{REFERENCES}

Ager, T.P. 2013. An introduction to synthetic aperture radar imaging. Oceanography 26(2):20-33, http://dx.doi.org/10.5670/oceanog.2013.28.

Alpers, W., and H.A. Espedal. 2004. Oils and surfactants. Pp. 263-275 in Synthetic Aperture Marine User's Manual. J.R. Apel and C.R. Jackson, eds, National Oceanic and Atmospheric Administration, Washington, DC. Available online at: http://www.sarusersmanual. com (accessed August 2, 2013).

Brekke, C., and A.H.S. Solberg. 2005. Oil spill detection by satellite remote sensing. Remote Sensing of Environment 95(1):1-13, http:// dx.doi.org/10.1016/j.rse.2004.11.015. 
Carpenter, A.D., R.G. Dragnich, and M.T. Smith. 1991. Marine operations and logistics during the Exxon Valdez spill cleanup. International Oil Spill Conference Proceedings 1991(1):205-211, http:// dx.doi.org/10.7901/2169-3358-1991-1-205

Cheng, A., M. Arkett, T. Zagon, R. De Abreu, D. Mueller, P. Vachon, and J. Wolfe. 2011. Oil detection in RADARSAT-2 quad-polarization imagery: Implications for ScanSAR performance. Proceedings SPIE 8179, SAR Image Analysis, Modeling, and Techniques XI, 81790G (October 26, 2011), http://dx.doi.org/ $10.1117 / 12.898358$

Espedal, H.A. 1999. Satellite SAR oil spill detection using wind history information. International Journal of Remote Sensing 20(1):49-65, http:// dx.doi.org/10.1080/014311699213596.

Fingas, M. 2013. The Basics of Oil Spill Cleanup, $3^{\text {rd }}$ ed. CRC Press, $286 \mathrm{pp}$.

Gade, M., W. Alpers, H. Hühnerfuss, H. Masuko, and T. Kobayashi. 1998. Imaging of biogenic and anthropogenic ocean surface films by the multifrequency/multipolarization SIR-C/X-SAR. Journal of Geophysical Research 103(C9):18,851-18,866, http:// dx.doi.org/10.1029/97JC01915.

Gambardella, A., G. Giacinto, M. Migliaccio, and A. Montali. 2010. One-class classification for oil spill detection. Pattern Analysis and Applications 13(3):349-366, http:// dx.doi.org/10.1007/s10044-009-0164-z.

Garcia-Pineda, O., I.R. MacDonald, X. Li, C.R. Jackson, and W.G. Pichel. 2013. Oil spill mapping and measurement in the Gulf of Mexico with Textural Classifier Neural Network Algorithm (TCNNA). IEEE Journal of Selected Topics in Applied Earth Observations and Remote Sensing PP(99):1-9, http://dx.doi.org/ 10.1109/JSTARS.2013.2244061.

Garcia-Pineda, O., I. MacDonald, B. Zimmer, B. Shedd, and H. Roberts. 2010. Remotesensing evaluation of geophysical anomaly sites in the outer continental slope, northern Gulf of Mexico. Deep Sea Research Part I 57:1,859-1,869, http://dx.doi.org/ 10.1016/j.dsr2.2010.05.005

Garcia-Pineda, O., B. Zimmer, M. Howard, W. Pichel, X. Li, and I.R. MacDonald. 2009. Using SAR images to delineate ocean oil slicks with a texture-classifying neural network algorithm (TCNNA). Canadian Journal of Remote Sensing 35(5):411-421, http://dx.doi.org/ 10.5589/m09-035.

Gauthier, M.-F., L. Weir, Z. Ou, M. Arkett, and R. De Abreu. 2007. Integrated satellite tracking of pollution: A new operational program. Pp. 967-970 in IEEE International Geoscience and Remote Sensing Symposium, July 23-28, 2007. IGARSS 2007, http://dx.doi.org/10.1109/ IGARSS.2007.4422960.

Holt, B. 2004. SAR Imaging of the ocean surface. Pp. 25-79 in Synthetic Aperture Marine User's Manual. C.R. Jackson and J.R. Apel, eds, National Oceanic and Atmospheric
Administration, Washington, DC. Available online at: http://www.sarusersmanual.com (accessed August 2, 2013).

Horstmann, J., and W. Koch. 2005. Measurement of ocean surface winds using synthetic aperture radars. IEEE Journal of Oceanic Engineering 30:508-515, http://dx.doi.org/ 10.1109/JOE.2005.857514.

Leifer, I., W.J. Lehr, D. Simecek-Beatty, E. Bradley, R. Clark, P. Dennison, Y. Hu, S. Matheson, C.E. Jones, B. Holt, and others. 2012. State of the art satellite and airborne marine oil spill remote sensing: Application to the BP Deepwater Horizon oil spill. Remote Sensing of Environment 124:185-209, http://dx.doi.org/ 10.1016/j.rse.2012.03.024.

McCandless, S.W., and C.R. Jackson. 2004. Principles of synthetic aperture radar. Pp. 1-23 in Synthetic Aperture Marine User's Manual. C.R. Jackson and J.R. Apel, eds., National Oceanic and Atmospheric Adminstration, Washington, DC. Available online at: http://www.sarusersmanual.com (accessed August 2, 2013).

Migliaccio, M., G. Ferrara, A. Gambardella, F. Nunziata, and A. Sorrentino. 2007a. A physically consistent speckle model for marine SLC SAR images. IEEE Journal of Oceanic Engineering 32(4):839-847, http:// dx.doi.org/10.1109/JOE.2007.903985.

Migliaccio, M., A. Gambardella, and M. Tranfaglia. 2007b. SAR polarimetry to observe oil spills. IEEE Transactions on Geoscience and Remote Sensing 45(2):506-511, http://dx.doi.org/ 10.1109/TGRS.2006.888097.

Migliaccio, M., F. Nunziata, and A. Gambardella 2009. On the co-polarized phase difference for oil spill observation. International Journal of Remote Sensing 30(6):1,587-1,602, http:// dx.doi.org/10.1080/01431160802520741.

NRC (National Research Council). 2003. Oil in the Sea III: Inputs, Fates, and Effects. Committee on Oil in the Sea: Inputs, Fates, and Effects. The National Academies Press, Washington, DC, $280 \mathrm{pp}$.

Nunziata, F., A. Gambardella, and M. Migliaccio. 2012. A unitary Mueller-based view of polarimetric SAR oil slick observation. International Journal of Remote Sensing 33(20):6,403-6,425, http://dx.doi.org/10.1080/01431161.2012. 687474.

Nunziata, F., A. Gambardella, and M. Migliaccio. 2013. On the degree of polarization for SAR sea oil slick observation. ISPRS Journal of Photogrammetry and Remote Sensing 78:41-49, http://dx.doi.org/10.1016/ j.isprsjprs.2012.12.007.

Raney, R.K. 2007. Hybrid-polarity SAR architecture. IEEE Transactions on Geoscience and Remote Sensing 45(11):3,397-3,404, http:// dx.doi.org/10.1109/TGRS.2007.895883.

Romeiser, R., J. Horstmann, M.J. Caruso, and H.C. Graber. 2013. A descalloping postprocessor for ScanSAR images of ocean scenes.
IEEE Transactions on Geoscience and Remote Sensing 51(6):3,259-3,272, http://dx.doi.org/ 10.1109/TGRS.2012.2222648.

Solberg, A.H.S. 2012. Remote sensing of ocean oil-spill pollution. Proceedings of the IEEE 100(10):2,931-2,945, http://dx.doi.org/ 10.1109/JPROC.2012.2196250.

Topouzelis, K.N. 2008. Oil spill detection by SAR images: Dark formation detection, feature extraction and classification algorithms. Sensors 8(10):6,642-6,659, http://dx.doi.org/ $10.3390 / \mathrm{s} 8106642$.

USCG (United States Coast Guard). 2011. On Scene Coordinator Report Deepwater Horizon. Available online at: http://www.uscg.mil/foia/ docs/DWH/FOSC_DWH_Report.pdf (accessed August 2, 2013).

Velotto, D., M. Migliaccio, F. Nunziata, and S. Lehner. 2011. Dual-polarized TerraSAR-X data for oil-spill observation. IEEE Transactions on Geoscience and Remote Sensing 49(12):4,751-4,762, http://dx.doi.org/ 10.1109/TGRS.2011.2162960.

Villano, M., G. Krieger, and A. Moreira. 2012. Staggered-SAR for high-resolution wideswath imaging. Paper presented at the IET International Conference on Radar Systems (Radar 2012), October 22-25, 2012, http:// dx.doi.org/10.1049/cp.2012.1600.

Wahl, T., A. Skoelv, and J.H.S. Andersen. 1994. Practical use of ERS-1 SAR images in pollution monitoring. International Geoscience and Remote Sensing Symposium, 1994. IGARSS '94. Surface and Atmospheric Remote Sensing: Technologies, Data Analysis and Interpretation 4:1,954-1,956, http://dx.doi.org/ 10.1109/IGARSS.1994.399621. 